\title{
Trade in Secondhand Goods and Recyclable Materials, Monitoring of Illegal Trade, and Import Quotas on Legal Trade*
}

\author{
Keisaku Higashida ${ }^{\dagger}$ \\ ${ }^{\dagger}$ School of Economics, Kwansei Gakuin University
}

\begin{abstract}
This paper theoretically examines the monitoring of illegal trade, and restrictions on the legal trade, of secondhand goods and recyclable materials. We demonstrate that (a) a stricter monitoring necessarily decreases the environmental damage of the importing country as far as there are no legal imports of recyclable materials, and (b) a stricter trade restriction on legal imports increases the environmental damage of the importing country if a part of legal imports is recyclable materials and the marginal environmental damage caused by illegal trade is serious. Moreover, we investigate the policy game on the choice of monitoring probabilities between trading countries.
\end{abstract}

JEL Classification: F13, F18, Q53

Key words: Illegal trade, monitoring, secondhand goods, recyclable materials, trade restriction

\section{Introduction}

Transboundary movement of secondhand goods and recyclable materials from developed to developing countries has increased substantially in the last few decades. ${ }^{1)}$ Importantly, these goods and materials frequently contain hazardous substances, and upon dismantling and recycling in developing countries, often account for serious environmental pollution. ${ }^{2}$ Further, in developing countries, the recycling sector is informal and usually unskilled-labor intensive.

Received 26 March 2020, Accepted 21 June 2020, Released online in J-STAGE as advance publication 4 September 2020.

* I would like to thank Toshiyasu Izawa, Takao Okawa, Hidefumi Yokoo, Taiji Furusawa and other participants at Nagoya International Economics Group Meeting at Chukyo University, The Second Spring Meeting of Japan Society of International Economics at Nanzan University, and the Workshop in memory of Professor Ohyama and Professor Ikema for helpful comments. I gratefully acknowledge financial support from Japan Society for the Promotion of Science under the Grant-in-Aid for Scientific Research (C).

$\dagger$ School of Economics, Kwansei Gakuin University, 1-155, Ichiban-cho, Uegahara, Nishinomiya, Hyogo 662-8501, Japan. Email: keisaku@kwansei.ac.jp

1) See Kellenberg (2010), Ray (2008), Shinkuma and Huong (2009), and Wong et al. (2007), among others, for real-world situations in the 1990s and 2000s concerning the trade in these goods and materials.

2) In the classification of international trade, such as the Harmonized Commodity Description and Coding System (HS) for tariff nomenclature, recyclable materials are classified as wastes and scrap. However, we use recyclable materials instead of wastes and scrap throughout this paper except when we refer to the literature, laws, and international agreements. 
Trade in Secondhand Goods and Recyclable Materials, Monitoring of Illegal Trade, and Import Quotas on Legal Trade

Persons engaged in recycling in developing countries prefer pecuniary gains to environmental protection and generally have little understanding of the toxicity of hazardous substances. ${ }^{3)}$ Therefore, they extract materials to acquire income without taking proper care of the environment. Overall, although these countries gain economic benefits from importation, their governments have realized that the loss from environmental degradation may outweigh the economic benefits. ${ }^{4)}$ Further, as they often face problems of the scarcity of landfills caused by the overflow of wastes, they have been considering policies that decrease import volumes and encourage recycling activities.

Theoretically, the best way to address this issue is to implement Pigouvian taxes in each importing country. However, we typically observe illegal activities (illegal recycling and illegal dumping) in several countries. Therefore, it is usually difficult for developing countries to effectively implement environmental taxes. In such cases, border measures, such as tariffs and import quotas, can be effective second-best policies. ${ }^{5)}$ In fact, several developing countries have restricted their trade, with some countries completely prohibiting the import of certain kinds of secondhand goods such as electric appliances, and recyclable materials such as wasted plastic and copper scrap. ${ }^{6}$ Several articles demonstrated the structure and networks of international trade in secondhand goods and recyclable materials and examined the impacts of import bans on these goods and materials by the importing countries. For example, Wang et al. (2019), Huan et al. (2020), and Wang et al. (2020) examined the trade of wasted plastics and Junbo et al. (2019) and Liu et al. (2020) examined that of copper wastes and scrap. They found that import restrictions are basically effective to decrease the imports of targeted materials, although the domestic supply of those materials in those countries cannot meet the demand-at least in the short run. ${ }^{7}$

Further, international regulations, such as the Basel Convention on the Control of Transboundary Movements of Hazardous Wastes and their Disposal stipulate trade restrictions on hazardous waste. Many secondhand goods, such as used computers, contain toxic substances. Therefore, the Basel Convention may apply to not only wastes but also in the trade of secondhand goods. The restrictions have become stricter in recent decades. For example, the Ban Amendment to the Basel Convention came into effect in December 2019. ${ }^{8)}$

However, as large volumes of secondhand goods and recyclable materials are traded ille-

3) See Ilankoon (2018) and Parajuly et al. (2018) for the case of E-waste (electronic and electrical wastes) recycling.

4) Kellenberg (2012) empirically demonstrated international waste haven effect: import volumes of countries with lax environmental regulations are likely to be large. Moreover, Kellenberg (2015) provided the review regarding the factors that influence trade in waste.

5) Copeland (1991) and Kinnaman and Yokoo (2011) referred to this point and examined trade policies as second-best policies.

6) See the website for the Asian Network for Prevention of Illegal Transboundary Movement of Hazardous Wastes for import controls on secondhand goods (https://www.env.go.jp/en/recycle/asian_net/About_ Asian_Network/index.html).

7) $\mathrm{Pu}$ et al. (2019) investigated the comprehensive trading networks of recyclable materials and demonstrated that recycling policies of importing countries have significant impacts on the structure of the networks.

8) See the website of the Basel Convention (http://www.basel.int/) for the details. The effect of the Basel Convention is controversial. For example, Kellenberg and Levinson (2014) empirically concluded that they found no evidence that the Basel Convention has decreased the trade in waste. 


\section{K. Higashida}

gally, simple trade restrictions on legal exports/imports may not function as effectively as intended. ${ }^{9)}$

Although exporters should formally remove hazardous substances prior to exportation when exporting recyclable materials, they occasionally skip this process. Thus, illegally traded materials are disguised as materials without including any hazardous substances. Observing this situation, monitoring policies should be examined. In fact, customs officers of importing countries inspect imports of recyclable materials, and we often observe the ship-back of secondhand goods or recyclable materials when customs officers of importing countries discover illegally traded products. Although monitoring systems do not work perfectly, strengthened monitoring can decrease illegal imports and environmental damage caused by those illegally traded goods and materials. For example, Sun (2019) empirically demonstrated that the stricter monitoring policy enforced by the Chinese government, Operation Green Fence, significantly decreased illicit trade.

In this paper, we examine monitoring policies on illegal trade and trade restrictions on legal trade in secondhand goods and recyclable materials. In particular, we focus on the effect of those policies on environmental damage in importing countries. In other words, assuming that environmental damage caused by imported secondhand goods and recyclable materials should be reduced in terms of the welfare of the importing countries, we investigate effective policies. Further, we examine the behavior of governments in choosing their monitoring probabilities simultaneously. Moreover, we consider if exporting or importing countries should commit to stricter monitoring activities.

There are three important features in our analysis. First, environmental and health damage are generated not only from recycling processes of recyclable materials but also from dismantling of secondhand goods. Moreover, when goods and materials are disposed into landfills, the scarcity of landfills may become serious. Legally imported goods and materials may include less hazardous substances than illegally imported ones. Thus, we distinguish among the sizes of marginal environmental damage generated by secondhand goods, legally imported recyclable materials, and illegally imported recyclable materials.

Second, developed countries benefit from the export of secondhand goods because they can alleviate the scarcity of landfills. On the other hand, when customs in an importing country detect illegal trade, exporters have to bear ship-back costs, which are occasionally high. Moreover, developed countries may be able to encourage legal exports of recyclable materials by monitoring the illegal trade by themselves. Thus, exporting countries also have an incentive to monitor the illegal export of secondhand goods and recyclable materials. ${ }^{10)}$

Third, we consider import quotas on legal imports, which include both secondhand goods and recyclable materials. In reality, importing countries often impose import restrictions specific to secondhand goods or recyclable materials. However, exporters can choose to export

9) Kellenberg and Levinson (2019) empirically demonstrated that corruption can cause misreporting of trade quantities, although they did not focus on trade in waste. This result may indicate that proliferation of corruption can cause a large amount of illegal trade.

10) In reality, the detection of illegal trade occasionally leads to diplomatic issues, including the complete prohibition of trade in recyclable materials for a certain period. The home government may also lose reputation, particularly when it joins an international environmental agreement. Although we do not consider these costs explicitly in the theoretical model, these factors also provide the governments of exporting countries incentives to monitor illegal exports. 
Trade in Secondhand Goods and Recyclable Materials, Monitoring of Illegal Trade, and Import Quotas on Legal Trade

discarded goods as secondhand goods or recyclable materials. Thus, import restrictions on secondhand goods occasionally result in an increase in the imports of recyclable materials and vice versa. In such a case, import restrictions on total imports of reusables and recyclables should be implemented. ${ }^{11)}$

In terms of associated literature, Cassing and Kuhn (2003) investigated the effect of trade restrictions with waste trading. Copeland (1991) also examined trade restrictions in the presence of illegal dumping. However, neither study distinguished between legal and illegal trade, and therefore, did not consider monitoring systems. Elsewhere, Clerides and Hadjiyiannis (2008), Kinnaman and Yokoo (2011), and Yokoo and Kinnaman (2013) focused on the effect of trade in durable goods and demonstrated policies that achieve efficiency. Honma (2019) investigated optimal tax-subsidy schemes in the presence of international recycling. ${ }^{2)}$ However, they also did not consider monitoring issues. As for monitoring, Harford (1978, 1987), Macho-Stadler and Pérez-Costirillo (2006), and Ino (2011) investigated enforcement policies when environmental policies are imperfectly enforceable. ${ }^{13)}$ However, to our best knowledge, few studies have addressed strategic monitoring and trade restrictions in the context of the trade in secondhand goods.

We demonstrate that a stricter monitoring — an increase in the monitoring probability — by an importing country necessarily decreases the environmental damage of the importing country when there is no legal imports of recyclable materials, while it may increase the environmental damage when a part of legal imports are recyclable materials. The increase in the environmental damage may arise because the stricter monitoring increases the legal trade of secondhand goods and recyclable materials - although it decreases illegal trade. Further, we demonstrate that a stricter trade restriction by an importing country on legal imports increases its environmental damage if a part of legal imports is recyclable materials and the marginal environmental damage caused by illegal trade is more serious than that caused by legal trade of recyclable materials. This situation may arise because a stricter import restriction on legal imports increases illegal trade. Moreover, we show that, in the simultaneous move equilibrium in which both governments choose the strictness of monitoring simultaneously, the monitoring probability of the exporting (importing) country is likely to be lower (higher) than that in the globally optimum, if the environmental damage of the exporting (importing) country is not serious (serious).

The rest of the paper is organized as follows. Section 2 describes the model and defines environmental damage. Section 3 examines the policy effect. We consider changes in two types of policies: monitoring of illegal trade and import restrictions. Section 4 investigates the

11) Governments occasionally control the quantity of imports of secondhand goods by setting an age limit whereby secondhand goods that exceed this limit cannot be legally imported. Although we do not consider the age of secondhand goods explicitly, an import quota in our paper is applicable to the trade restriction with an age limit in the real world. For example, see the following page on the website of the Ministry of the Environment Japan, for the case of Thailand. (https://www.env.go.jp/en/recycle/asian net/Country_Information/Law $\$ N_Regulation/Thailand_of_Law_and_Regulation.html)

12) Chatterjee et al. (2015) compared taxes and standards in the presence of a recycling sector. However, they primarily focus on one small open economy, and neither monitoring policies nor strategic relationship between trading countries is considered.

13) Shimshack (2014) provided the review on environmental enforcement and monitoring institutions, theories, and empirical evidenec on deterrence effects. 


\section{K. Higashida}

scenario in which both governments noncooperatively choose their monitoring probabilities. Section 5 provides some concluding remarks.

\section{The Model}

Consider a developed country, referred to as the home country, and a developing country, referred to as the foreign country. The home (foreign) country exports (imports) secondhand goods $(X)$ and recyclable materials extracted from goods $X$ discarded by home consumers. For simplicity, we assume that there is no demand for secondhand goods or recyclable materials in the home country. ${ }^{14)}$ Further, we assume that there is no supply of secondhand goods in the foreign country. ${ }^{15)}$ Consumers in the home country use new goods $X$ for one period, after which they are discarded. On the other hand, consumers in the foreign country may purchase new or secondhand goods and use them for one period, discarding them after use. For simplicity, the number of consumers and accordingly, the quantities of consumption of goods $X$ in the home country are fixed and constant.

\subsection{Supply of Secondhand Goods and Recyclable Materials}

The supply of discarded goods $(X)$ in the home country is constant, denoted by $X_{s}$. Collectors in the home country collect discarded goods from consumers. No collector has market power. Collectors then have three alternatives: (i) exporting the collected goods to the foreign country legally, (ii) exporting them to the foreign country illegally, or (iii) disposing them into landfills in the home country.

When collectors export discarded goods legally, they have two alternatives: (i) exporting them as secondhand or (ii) exporting them as recyclable materials. When exporting them as secondhand, they have to repair the goods. ${ }^{16)}$ When exporting them as recyclable materials, they have to remove hazardous substances based on the regulation set by the importing country or an international agreement such as the Basel Convention. We consider a situation in which there is heterogeneity in the costs of repairing and removing hazardous substances among collectors. Assuming that each collector collects one unit of discarded goods, and that one unit of discarded goods contains one unit of material, the marginal costs of collectors when exporting goods as secondhand are represented as

$$
m c_{u, i}, \quad i=1,2, \cdots, N,
$$

where $u$ denotes exporting legally as secondhand, and $i$ denotes the index for collectors. Moreover, it holds that

$$
m c_{u, j}>m c_{u, k}, \quad j=k+1, \quad k=1,2, \cdots, N-1 .
$$

14) For example, the recycling industry that use this type of recyclable material as inputs may exist only in a developing country. However, even if we drop these assumptions, the results do not change essentially.

15) For example, the quality of new goods sold in the foreign country may be low, or maintenance or repair services may not be well supplied in the foreign country while consumers use new goods. In such cases, new goods $X$ that have already been used for one period cannot be used as secondhand. Nevertheless, even if we drop these assumptions, the results do not change essentially.

16) In reality, they may have to repair discarded goods because customs officers in the importing country often regard broken goods not as secondhand goods but as wastes. In such cases, importation is not permitted. 
Trade in Secondhand Goods and Recyclable Materials, Monitoring of Illegal Trade, and Import Quotas on Legal Trade

For simplicity, we avoid the integer problem. Then, as far as there are no legal exports of recyclable materials, the marginal cost curve of repairing and exporting as secondhand legally is given by

$$
M C_{u}=M C_{u}\left(X_{u}\right), \quad M C_{u}^{\prime}>0,
$$

where $X_{u}$ denotes the quantity of legal exports as secondhand. In this situation, the quantity of legal exports of secondhand goods is determined so that the price of secondhand goods in the foreign market, $p_{u}$, is equal to the marginal cost, $M C_{u}$. Thus, the supply curve of legal exports of secondhand goods is given by

$$
X_{u}=X_{u}\left(p_{u}\right), \quad X_{u}^{\prime}>0
$$

We also assume that each collector's cost of exporting legally as recyclable material is given by

$$
m c_{u, i}-r, \quad i=1,2, \cdots, N
$$

where $r$ is a positive constant. ${ }^{17)}$ Thus, as far as there are no legal exports of secondhand goods, the marginal cost curve of removing hazardous substances and exporting legally is given by

$$
M C_{m}=M C_{u}\left(X_{m}\right)-r
$$

where $X_{m}$ denotes the quantity of legal exports as recyclable materials. In this situation, the quantity of legal exports of recyclable materials is determined so that the price of secondhand goods in the foreign market, $p_{m}$, is equal to the marginal cost, $M C_{u}-r$. Thus, the supply curve of legal exports of secondhand goods is given by

$$
X_{m}=X_{m}\left(p_{m}\right), \quad X_{m}^{\prime}=X_{u}^{\prime}>0 .
$$

For simplicity, we assume the linearity of both supply curves: $X_{u}^{\prime \prime}=X_{m}^{\prime \prime}=0$. Note that the shipping cost is included in $M C_{u}$ and $M C_{m}{ }^{18)}$

When both secondhand goods and recyclable materials are exported legally, home collectors choose whether they export discarded goods as secondhand goods or recyclable materials. Home collectors choose to export secondhand goods if $p_{u}-r>p_{m}$, while they choose to export recyclable materials if $p_{u}-r<p_{m}$. Thus, $p_{u}-r=p_{m}$ holds in equilibrium. Consequently, the quantity of total legal exports is given by

$$
X_{l}=X_{l}\left(p_{m}\right), \quad \text { or } \quad X_{l}=X_{l}\left(p_{u}\right), \quad X_{l}^{\prime}=X_{u}^{\prime}>0,
$$

where $p_{u}-r=p_{m}$. As explained below, the quantity of each type of legal exports, secondhand goods, or recyclable materials depends on the demand and import quota.

When collectors export discarded goods illegally, they are obliged to disguise the discarded goods as recyclable materials that do not contain any hazardous substances. Thus, each collector has to pay a disguising cost per unit, $C_{d}$, which is constant and common for all collec-

17) We implicitly assume that the orders of collectors by the repairing cost and by the cost of removing hazardous substances are the same. Although we assume the former cost is higher than the latter, whether $r$ is positive or negative does not affect the results.

18) We do not explicitly describe transactions between home consumers and collectors. Implicitly, we consider a situation in which the government sets a disposal fee on one unit of good $X$ for consumers. Consumers then have an incentive to pay a collection fee to collectors if the collection fee is at most equal to the disposal fee. 


\section{K. Higashida}

tors. The shipping cost is also included in $C_{d}$. We assume that the supply of discarded goods in the home country is sufficiently large such that illegal trade necessarily exists. As explained later, the governments monitor illegal trade and, accordingly, illegal exports may be exposed. In such a case, home collectors must pay fines. Moreover, when they are identified by the foreign government, home collectors must return those goods to the home country, and thus, bear the ship-back costs.

These alternatives reflect the following situation. In general, recycling is usually very costly in developed countries, whereas it is much cheaper in developing countries. This is partly because recycling is often conducted using unskilled labor, even though this type of recycling can cause serious environmental and health damage. Moreover, the demand for recyclable materials is often significant in developing countries even if they are imported illegally. When home collectors export discarded goods illegally, there is a risk of being exposed. In such cases, as mentioned earlier, home collectors must pay fines and ship-back costs. However, they can save the cost of removing hazardous substances when illegal exports are not identified. Thus, they have an incentive to export collected goods either legally or illegally. When exported illegally, in general, hazardous substances are not removed before exportation, and foreign recyclers extract recyclable materials from those illegally exported goods. ${ }^{19)}$

In the foreign country, there is no supply of discarded goods for secondhand use, while there is a supply of discarded goods as recyclable materials to the foreign market. ${ }^{20)}$ The marginal cost of supplying recyclable materials by foreign collectors is given by

$$
M C_{F}=M C_{F}\left(X_{F}\right), \quad M C_{F}^{\prime}>0,
$$

where $X_{F}$ denotes the quantity of supply of recyclable materials by foreign collectors. Foreign collectors also face the market price of recyclable materials, $p_{m}$. Thus, the supply curve of foreign collectors is

$$
X_{F}=X_{F}\left(p_{m}\right), \quad X_{F}^{\prime}>0 .
$$

For simplicity, we assume the linearity of this supply curve: $X_{F}^{\prime \prime}=0$.

\subsection{Demand for Secondhand Goods and Recyclable Materials}

There are two types of demand for discarded goods in the foreign country: as secondhand goods and recyclable materials. The inverse demand curve of goods $X$ for secondhand use in the foreign market is given by

$$
p_{u}=P_{u}\left(D_{u}\right), \quad P_{u}^{\prime}<0,
$$

where $D_{u}$ denotes the quantity of legal imports used as secondhand and, accordingly, the consumption quantity of secondhand goods in the foreign country. On the other hand, the inverse demand curve of goods $X$ as recyclable materials in the foreign market is given by

$$
p_{m}=P_{m}\left(D_{m}\right), \quad P_{m}^{\prime}<0,
$$

where $D_{m}$ denotes the consumption quantity of recyclable materials, which is equal to the sum

19) See Shinkuma and Managi (2011) for a comprehensive analysis of waste and recycling.

20) Wang et al. (2019), Huan et al. (2020), Wang et al. (2020), Junbo et al. (2019), and Liu et al. (2020) also referred to the importance of recycling policies in developing countries. Thus, it is important to consider this domestic supply of recyclable materials. 
Trade in Secondhand Goods and Recyclable Materials, Monitoring of Illegal Trade, and Import Quotas on Legal Trade

of legal imports as recyclable materials, illegal imports, and the foreign domestic supply.

From (8) and (9), the demand curves are obtained:

$$
\begin{aligned}
D_{u} & =D_{u}\left(p_{u}\right), \quad D_{u}^{\prime}<0, \\
D_{m} & =D_{m}\left(p_{m}\right), \quad D_{m}^{\prime}<0 .
\end{aligned}
$$

For simplicity, we assume the linearity of both demand curves: $D_{u}^{\prime \prime}=D_{m}^{\prime \prime}=0$.

\subsection{Policies}

We consider two kinds of policies for the foreign government. First, the foreign government may set an import quota on legal imports, denoted by $\bar{X}_{l}$. As described in the introduction, in the real world, developing countries often ban the import of secondhand goods and recyclable materials. Therefore, it is important to clarify the effect of import restrictions on environmental damage. ${ }^{21)}$

Second, both home and foreign governments monitor illegal trade. As illegal exports are disguised as recyclable materials without hazardous substances, the government must inspect all kinds of traded secondhand goods and recyclable materials. However, customs officials may not be able to identify illegal trade with certainty. We let $\alpha_{h}$ and $\alpha_{f}$ denote the monitoring probabilities chosen by the home and foreign governments, respectively; more precisely, the products of the probabilities of monitoring and identifiability. ${ }^{22}$

It is costly for the governments to monitor exports/imports. Moreover, when the government identifies illegally traded goods, it must temporarily retain them before returning them to the home collectors. In addition, the foreign government makes collectors ship these goods back to the home country. Hence, the operating cost of the monitoring system increases with the expected amount of identified illegal trade. Therefore, we assume that the expected amount depends on the strictness of monitoring, $\alpha_{\sigma}(\sigma=h, f)$. Thus, the expected operating cost of the monitoring system is

$$
E\left[C_{G, \sigma}\right]=E\left[C_{G, \sigma}\left(\alpha_{\sigma}\right)\right], \quad \sigma=h, f .
$$

Note that the combinations of $E$ and square brackets denote expected values. We set up the following assumption on the shape of this cost function.

\section{Assumption 1}

$$
\frac{\partial E\left[C_{G, \sigma}\right]}{\partial \alpha_{\sigma}} \geq 0, \quad \frac{\partial^{2} E\left[C_{G, \sigma}\right]}{\partial \alpha_{\sigma}^{2}}>0, \quad \frac{\partial E\left[C_{G, \sigma}\right]}{\partial \alpha_{\tau}}=0,
$$

where $\sigma, \tau=h, f, \sigma \neq \tau$.

21) The home government can set an export restriction. However, importing countries and/or international environmental agreements usually attempt to set stricter restrictions. This is because importing countries suffer most from any environmental/health damage arising from pollution caused by imported secondhand goods. In such cases, exporting countries respect the restrictions set by the importing countries. Thus, we focus on trade restrictions set by the importing country.

22) Using the data in Italy, D'Amato (2015) empirically demonstrated that the existence of organized crime spoils the effectiveness of waste management policies. Thus, it is possible that customs officers intentionally overlook illegal trade, which decreases the monitoring probability. 


\section{K. Higashida}

The first two inequalities are intuitive. The probability of home (foreign) monitoring does not affect the foreign (home) monitoring cost either: refer to the third equality. Moreover, the total quantity of traded recyclable materials, which are classified as waste and scrap, according to trade classifications, is significant. Quantities of secondhand goods and recyclable materials relating to goods $X$ do not influence the operating cost, because the ratio of those quantities to the total quantity of traded recyclable materials is small.

The fines imposed by the governments for each unit of identified illegal exports/imports is $F_{\sigma}(\sigma=h, f){ }^{23)}$ In this model, we assume these fines are exogenous because the level of the fine for the illegal export/import should be in accordance with fines for other types of illegal activities. Thus, we exclude an infinitely large fine. ${ }^{24)}$

\subsection{Expected Marginal Cost and Quantity of Illegal Trade}

By considering the monitoring by both governments, we redefine the cost of illegal export. The expected marginal cost of illegal export $\left(E\left[M C_{i l}\right]\right)$ is greater than $C_{d}$ in the presence of monitoring:

$$
E\left[M C_{i l}\right]=C_{d}+\alpha_{h} F_{h}+\left(1-\alpha_{h}\right) \alpha_{f}\left(F_{f}+\lambda\right),
$$

where $\lambda$ denotes the ship-back cost. Note that $\partial E\left[M C_{i l}\right] / \partial \alpha_{f}>0$. We set up the following assumption.

Assumption $2 \partial E\left[M C_{i l}\right] / \partial \alpha_{h}>0$, i.e., $F_{h}-\alpha_{f}\left(F_{f}+\lambda\right)>0$.

This assumption implies that an increase in the home identifying probability increases the expected cost of illegal export for home collectors.

As home collectors choose whether they export recyclable materials legally or illegally, the marginal cost of exporting recyclable materials legally is equal to the expected illegally exporting cost ((13)) in equilibrium. They are also equal to $p_{m}$ in equilibrium. Let $X_{i l}$ denote the ex-post/actual quantity of illegal exports. The quantity that home collectors attempt to export illegally is larger than $X_{i l}$ because some of illegally exported materials are identified by customs officers of both countries. Thus, the quantity that home collectors attempt is given by

$$
\frac{X_{i l}}{\left(1-\alpha_{f}\right)\left(1-\alpha_{h}\right)} \text {. }
$$

Then, the quantity of illegal exports that is identified by the home government is given by

$$
\frac{\alpha_{h} X_{i l}}{\left(1-\alpha_{f}\right)\left(1-\alpha_{h}\right)}
$$

and that by the foreign government is given by

23) Not only importing but also exporting countries impose fines. For example, in Japan, the Waste Disposal and Public Cleaning Law stipulates fines for the illegal export of secondhand goods and recyclable materials. See the Ministry of the Environment's website (http://www.env.go.jp/en/laws/recycle/index. html).

24) The possibility of mistaken arrest also provides a basis for the argument that fines should not be infinitely large. 
Trade in Secondhand Goods and Recyclable Materials, Monitoring of Illegal Trade, and Import Quotas on Legal Trade

$$
\alpha_{f} \cdot\left(1-\alpha_{h}\right) \cdot \frac{X_{i l}}{\left(1-\alpha_{f}\right)\left(1-\alpha_{h}\right)}=\frac{\alpha_{f} X_{i l}}{1-\alpha_{f}} .
$$

We assume that these identified goods are disposed into landfills of the home country.

\subsection{Foreign Environmental Damage}

The focus of this paper is environmental and health damage in developing countries caused by importation of secondhand goods and recyclable materials. Thus, we define foreign environmental damage in the present context. Imports of discarded goods $X$ may cause environmental damage in the foreign country whether they are imported as secondhand or recyclable materials.

First, when discarded goods are legally imported for secondhand use, they may replace new products. In such a case, they may not increase environmental damage. If the contents of hazardous and other non-recyclable substances of legally imported secondhand goods are fewer than those in the replaced new goods, legally imported secondhand goods may even decrease foreign environmental damage. However, legal imports of secondhand goods may increase the total consumption quantity in the foreign country. In such a case, because they will be recycled in the future, even if technology and environmental management may progress, they may increase environmental damage. For example, Chen et al. (2019) examined the effect of Mexico's imports of secondhand vehicles from the US on total emission. They disaggregate the effect into scale, composition, and technique effects, and demonstrate that used vehicle imports decrease total emission: that is, the technique effect, arising from the replacement of originally used vehicles with more environmentally friendly imported secondhand vehicles, dominates the other two effects that increase pollution emission. ${ }^{25)}$

Second, when discarded goods are imported as recyclable materials, although hazardous substances are removed before exporting, recycling activities in the foreign country generate wastes. Thus, legal imports of recyclable materials also increase foreign environmental damage.

Third, when discarded goods are imported illegally, in addition to waste, hazardous substances are generated during recycling processes. Moreover, an increase in the foreign supply of recyclable materials $\left(X_{F}\right)$ decreases foreign environmental damage because the amount of waste disposed into foreign landfills decreases.

In total, foreign environmental damage is defined as

$$
E\left[e_{f}\right]=\mu_{u, f} \cdot X_{u}+\mu_{m, f} \cdot X_{m}+\mu_{i l, f} X_{i l}-\mu_{w, f} \cdot X_{F},
$$

where $\mu_{u, f}, \mu_{m, f}, \mu_{i l, f}$, and $\mu_{w, f}$ denote the marginal environmental damage caused by one unit of legal imports as secondhand goods, one unit of legal imports as recyclable materials, one unit of illegal imports, and one unit of wastes disposed into foreign landfills, respectively. ${ }^{26)}$ From the description above, $\mu_{u, f}$ may be positive or negative. On the other hand, $\mu_{m, f}$,

25) We consider that (i) the scarcity of landfills and (ii) the leakage of toxic substances from landfills are environmental problems. When the amount of wastes increases, the space for landfills becomes scarcer, and the risk of leakage becomes higher.

26) Equation (17) assumes constant marginal environmental damages $\left(\mu_{u, f}, \mu_{m, f}, \mu_{i l, f}\right.$, and $\left.\mu_{w, f}\right)$. However, they may be increasing in reality. Many previous studies have also adopted the increasing marginal environmental damage in their theoretical models. Even if we adopt increasing marginal environmental 


\section{K. Higashida}

$\mu_{i l, f}$, and $\mu_{w, f}$ are positive. In general, the following inequalities are considered to hold:

$$
\mu_{i l, f}>\mu_{m, f}, \quad \mu_{i l, f}>\mu_{u, f} .
$$

\section{Policy Effects on Foreign Environmental Damage}

We now investigate whether monitoring an import quota can decrease foreign environmental damage.

\subsection{Division into Four Cases}

Depending on whether the import quota $\bar{X}_{l}$ is binding and if a positive quantity of legal imports of recyclable materials exists, there are four possible cases.

Case 1: The import quota is binding and a part of legal imports are recyclable materials.

Case 2: The import quota is binding and no legal imports are recyclable materials.

Case 3: The import quota is not binding and a part of legal imports are recyclable materials.

Case 4: The import quota is not binding and no legal imports are recyclable materials.

In Case 1, the import quota is binding and the markets of secondhand goods and recyclable materials are integrated. Thus, the following conditions hold in equilibrium:

$$
\begin{gathered}
p_{u}-r=p_{m}=E\left[M C_{i l}\right], \\
X_{u}=D_{u}\left(p_{u}\right), \quad X_{m}=\bar{X}_{l}-X_{u}, \\
\bar{X}_{l}+X_{F}\left(p_{m}\right)+X_{i l}=D_{u}\left(p_{u}\right)+D_{m}\left(p_{m}\right) .
\end{gathered}
$$

See Figure 1 for this situation. The definition of the marginal cost of illegal exports $((13))$ indicates that $p_{m}$ and $p_{u}$ are determined by the monitoring policies of both governments $\left(\alpha_{\sigma}, \sigma=h, f\right)$. Then, the consumption of imported goods as secondhand and the quantity of illegal exports are determined by the equilibrium conditions, (20) and (21).

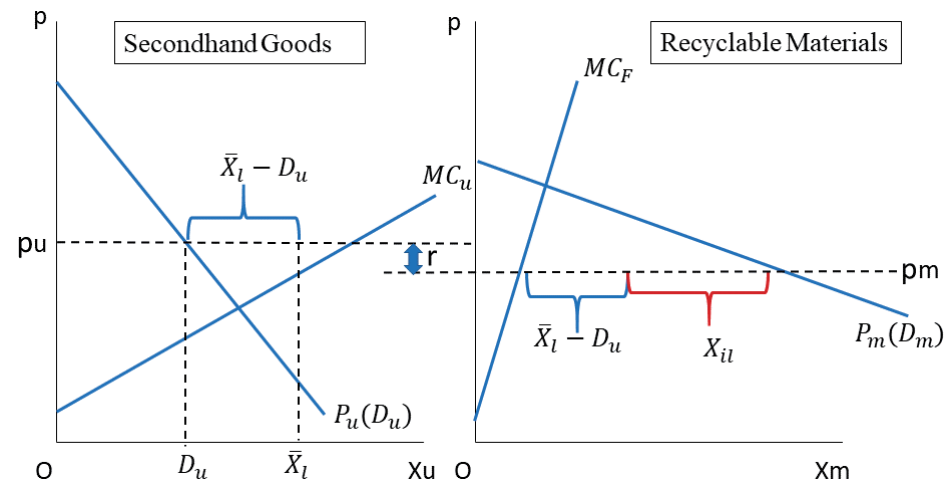

Figure 1: Import quota is binding, and a part of legal imports are recyclable materials (Case 1)

damages, the results do not change essentially. Thus, for simplicity and clarity, marginal environmental damages are assumed to be constant. 
Trade in Secondhand Goods and Recyclable Materials, Monitoring of Illegal Trade, and Import Quotas on Legal Trade

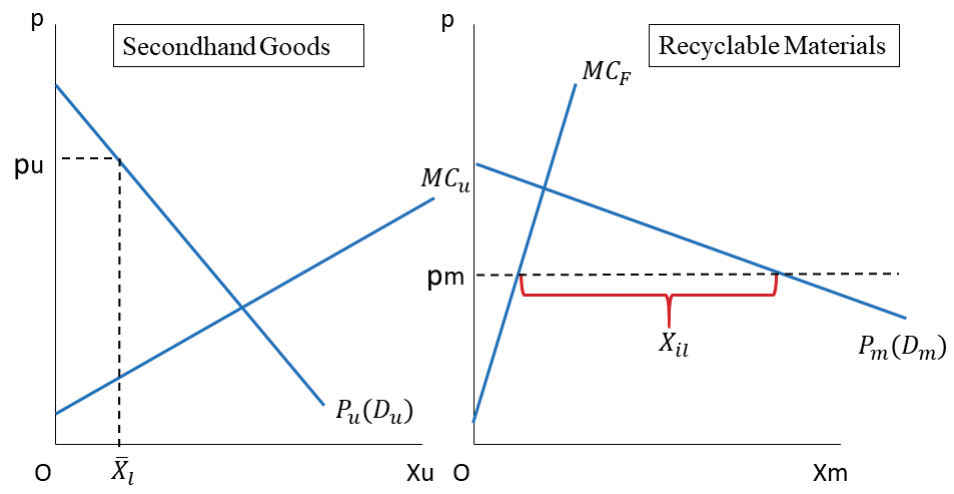

Figure 2: Import quota is binding, and no legal imports are recyclable materials (Case 2)

In Case 2, similar to Case 1, the import quota is binding. However, the markets of secondhand and recyclable materials are separated. Thus, the following conditions hold in equilibrium:

$$
\begin{gathered}
p_{m}=E\left[M C_{i l}\right], \\
X_{u}=\bar{X}_{l}, \quad X_{m}=0, \\
X_{F}\left(p_{m}\right)+X_{i l}=D_{m}\left(p_{m}\right) .
\end{gathered}
$$

See Figure 2 for this situation. In this case, the supply of recyclable materials to the foreign market comes from illegal imports or foreign collectors. From (7) and (22), the quantity of foreign domestic supply is obtained. Then, from (24), the quantity of illegal exports is obtained.

Analogous to the first two cases, the equilibrium conditions for Case 3 are given by

$$
\begin{gathered}
p_{u}-r=p_{m}=E\left[M C_{i l}\right], \\
X_{u}=D_{u}\left(p_{u}\right), \quad X_{l}=X_{l}\left(p_{m}\right), \\
X_{l}-X_{u}+X_{F}\left(p_{m}\right)+X_{i l}=D_{m}\left(p_{m}\right) .
\end{gathered}
$$

See Figure 3 for this situation. It should be noted that, in this case, some legal exports $\left(X_{u}\right)$ are

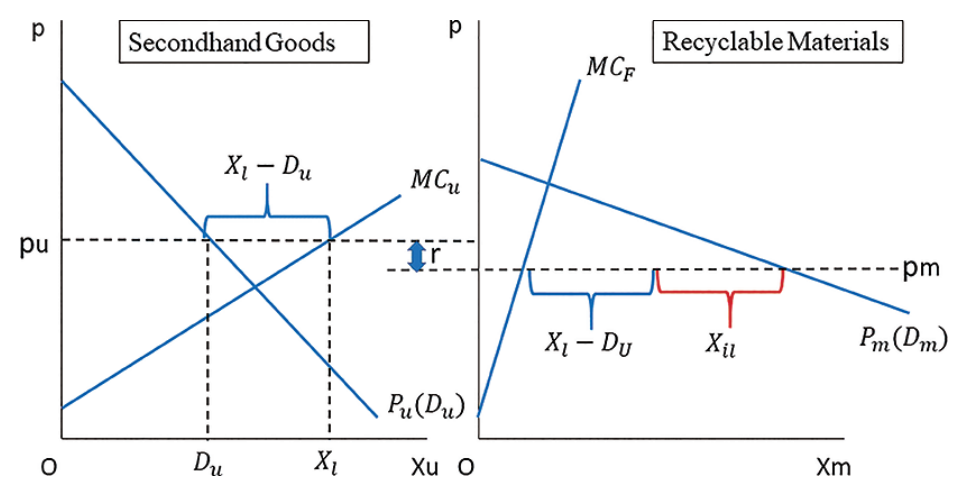

Figure 3: Import quota is not binding, and a part of legal imports are recyclable materials (Case 3) 


\section{K. Higashida}

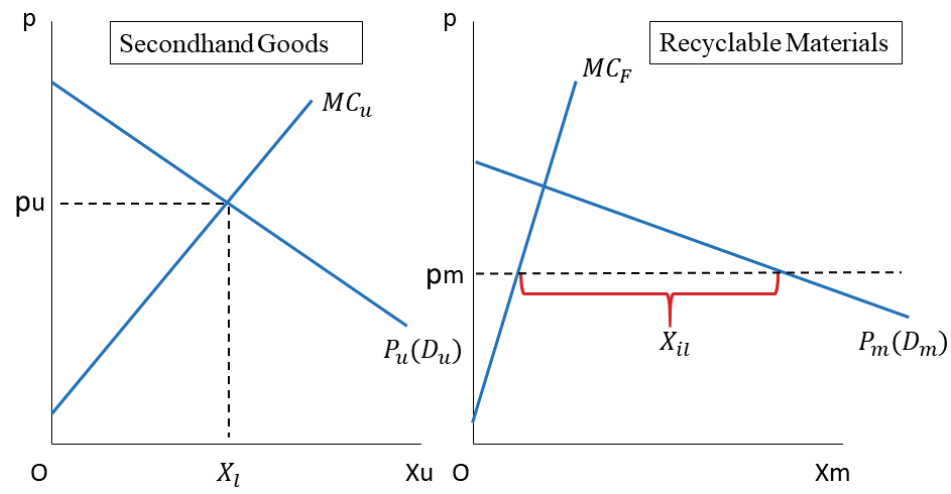

Figure 4: Import quota is not binding, and no legal imports are recyclable materials (Case 4)

secondhand goods, while others $\left(X_{l}-X_{u}\right)$ are recyclable materials. From (27), the quantity of illegal exports is obtained.

Finally, the equilibrium conditions for Case 4 are given by

$$
\begin{gathered}
p_{m}=E\left[M C_{i l}\right], \\
X_{l}=X_{u}=D_{u}\left(p_{u}\right), \\
X_{F}\left(p_{m}\right)+X_{i l}=D_{m}\left(p_{m}\right) .
\end{gathered}
$$

See Figure 4 for this situation.

\subsection{Strictness of Monitoring}

First, we examine the effect of an increase in the monitoring probability by the foreign government. ${ }^{27)}$ In the beginning, the following two facts should be noted. First, an increase in the probability of monitoring increases the expected marginal cost of illegal exports for home collectors (see (13)). The increase in the expected cost works for increasing legal exports of recyclable materials because legal and illegal exports as recyclable materials are substitutes for home collectors. Second, the first fact reveals that (i) when an import quota is binding, and/or (ii) no legal exports are recyclable materials, an increase in the monitoring probability does not affect the quantities of legal exports.

In Case 1, Equation (19) reveals that an increase in monitoring probability increases the expected marginal cost of illegal exports and, accordingly, both $p_{u}$ and $p_{m}$. These price changes lead to decreases in consumption quantities of secondhand goods $\left(D_{u}\right)$ and recyclable materials $\left(D_{m}\right)$ in the foreign country. As the import quota is binding, the legal exports of recyclable materials $\left(X_{m}\right)$ increase. An increase in $p_{m}$ also leads to an increase in the foreign domestic supply of recyclable materials $\left(X_{F}\right)$. Thus, it is obtained from (21) that the illegal exports decrease and, accordingly, the decreased quantity of illegal exports is greater than the increased quantity of legal exports of recyclable materials. Consequently, from (17), if (i) $\mu_{i l, f}>\mu_{m, f}$ and (ii) $\mu_{u, f}>0$ hold, an increase in the monitoring probability necessarily decreases foreign environmental damage. On the other hand, when these conditions are not satisfied, an increase

27) Regarding the effect on the foreign environmental damage, an increase in the monitoring probability by the home government has the same effect. 
Trade in Secondhand Goods and Recyclable Materials, Monitoring of Illegal Trade, and Import Quotas on Legal Trade

in the monitoring probability may increase foreign environmental damage.

In Case 2, because the import quota is binding and all legal exports are secondhand goods, an increase in the monitoring probability does not influence the quantity of legal exports. The expected marginal cost of illegal exporting increases, and $p_{m}$ increases. Then, the quantity of illegal exports $\left(X_{i l}\right)$ decreases and the foreign domestic supply of recyclable material increases. Consequently, it is obtained from (17) that foreign environmental damage necessarily decreases.

The effect in Case 3 is similar to that in Case 1. The difference between the two cases is the effect on legal exports. In Case 3, because the import quota is not binding, legal exports increase as $p_{m}$ increases (see (5) and (26)). Because the consumption of secondhand goods decreases, the export quantity of recyclable materials necessarily increases. However, Equation (27) indicates that illegal exports necessarily decrease. Thus, the same results as those for Case 1 are obtained.

The effect in Case 4 is the same as in Case 2. Although the import quota is not binding, no legal imports are recyclable materials. As monitoring by the foreign government influences the foreign market of recyclable materials, there is no impact on legal exports.

Proposition 1 An increase in the foreign monitoring probability ( $\left.\alpha_{f}\right)$ (i) necessarily decreases the foreign environmental damage when no legal imports are recyclable materials, while (ii) may increase foreign environmental damage when a part of legal imports are recyclable materials. In particular, an increase in foreign environmental damage may be observed when $\mu_{u, f}<0$ holds.

The last remark in Proposition 1 implies that, if the use of secondhand goods replaces the consumption of environmentally unfriendly new goods in the foreign country, an increase in the monitoring probability may deteriorate the foreign environment by discouraging this replacement. As described in Subsection 2.5, in the case of Mexico's used vehicles imports demonstrated by Chen et al. (2019), this condition is considered to hold.

Proposition 1 also provides an important policy implication. In the last decade, several Asian countries, such as China, have tightened import restrictions on recyclable materials. The results for Cases 2 and 4 in Proposition 1 indicates that the monitoring on illegal imports of recyclable materials functions as intended for decreasing environmental damage if the monitoring is enforced with these strict trade restrictions. ${ }^{28)}$

\subsection{Import Quotas}

Next, we examine the effect of stricter trade restrictions: a decrease in $\bar{X}_{l}$. We focus on the cases in which the import quota is binding, that is, Cases 1 and 2.

28) This complementarity of monitoring and trade restrictions is also related to the literature on the effect of strict environmental regulations. For example, focusing on toxic waste management in the US, Alberni and Austin (1999) demonstrated that, for some chemicals, spills are serious in states with strict liability. Almer and Goeschl (2010) found the evidence that criminal sanctions accompanying environmemntal policies have deterrence effects. Moreover, Stafford (2003) investigated the effect of strong liability regarding hazardous waste regulations on violation. In the present context, whether strict regulations, that is, trade restrictions, function effectively depends on the strict enforcement of monitoring on illegal activities. 


\section{K. Higashida}

In Case 1 , from (19), a change in $\bar{X}_{l}$ does not influence $\left(p_{u}\right)$ and $\left(p_{m}\right)$, which implies that the consumption quantities of secondhand goods and recyclable materials do not change. Moreover, the foreign domestic supply of recyclable materials does not change. A stricter trade restriction implies a decrease in $\bar{X}_{l}$. Thus, Equation (21) indicates that a decrease in legal exports in recyclable materials caused by a stricter trade restriction is completely cancelled out by an increase in the illegal exports. Consequently, if $\mu_{i l, f}>\mu_{m, f}$ holds, foreign environmental damage necessarily increases.

In Case 2, it is clear from (22) and (24) that a stricter trade restriction does not influence the foreign domestic supply of recyclable materials and illegal exports. Then, it is obtained from (23) that legal exports of secondhand goods decreases. Thus, if $\mu_{u, f}>0$ holds, foreign environmental damage necessarily decreases.

Proposition 2 Suppose that the import quota set by the foreign government is binding. Then, a stricter trade restriction on legal imports (i) increases the foreign environmental damage if (a) a part of legal imports are recyclable materials and (b) $\mu_{i l, f}>\mu_{m, f}$, while (ii) decreases the foreign environmental damage if (c) no legal imports are recyclable materials and (d) $\mu_{u, f}>0$.

Proposition 2 provides three policy implications. The first is the complementarity of trade restrictions on secondhand goods and recyclable materials. When trade in recyclable materials are strictly restricted, trade restrictions on secondhand goods may function efficiently in terms of mitigation of environmental damage.

Second, the smaller the $\alpha_{f}$, the larger the gains from illegal trade, and accordingly, the smaller the quantity of legal trade. This implies that a decrease in $\alpha_{f}$ increases the possibility that the trade restriction is nonbinding, given $\bar{X}_{l}$. Therefore, the trade restriction cannot be effective when monitoring systems do not function well.

Third, it is occasionally pointed out in the literature that when illegal activities cannot be punished with certainty, a trade restriction is justified to achieve the second-best outcome. ${ }^{29)}$ On the other hand, in the present case, because both legal and illegal imports generate environmental damage, a trade restriction may induce an increase in environmental damage. Therefore, a trade restriction is not always justified.

\section{Noncooperative Choices of Monitoring Probabilities}

In this section, assuming that the level of trade restriction $\left(\bar{X}_{l}\right)$ is exogenous, we consider the situation in which the governments choose the monitoring probabilities $\left(\alpha_{\sigma}(\sigma=h, f)\right)$ to maximize the welfare of their own countries. ${ }^{30)}$ For clarity of analysis and applicability to real-world situations, we focus on the case in which an import quota is binding, and part of the legally imported goods are recyclable materials (Case 1). ${ }^{31)}$

29) For example, see Copeland (1991).

30) The exogeneity of the import quota may correspond to situations in which trade restrictions are stipulated by international environmental agreements.

31) Theoretically, similar results hold for the other three cases. 
The home expected welfare is defined as the producer surplus of home collectors less the fine payment to the foreign government, the ship back cost, the cost due to failure of illegal exports, the home environmental damage, and the policy enforcing $\operatorname{cost}\left(E\left[C_{G, h}\right]\right)$. The meaning of failure of illegal exports is as follows. If illegal exports are not identified either by the home or the foreign government, the expected exporting cost is equal to the selling price, $p_{m}$. Thus, there is no loss from unidentified illegal exports. However, if illegal exports are identified, collectors cannot sell them. Thus, the disguising cost they paid is net loss for home collectors. The home environmental damage depends on the amount of discarded goods that are disposed into home landfills, that is, $X_{s}-X_{l}-X_{i l}$. Thus, the home expected welfare is given by

$$
\begin{aligned}
E\left[W_{h}\right]= & \int_{0}^{X_{l}}\left(p_{m}-M C_{l, m}(\zeta)\right) d \zeta-\frac{\alpha_{f}}{1-\alpha_{f}} \cdot\left(F_{f}+\lambda\right) \cdot X_{i l}-\frac{\alpha_{h}+\alpha_{f}-\alpha_{h} \alpha_{f}}{\left(1-\alpha_{h}\right)\left(1-\alpha_{f}\right)} \cdot C_{d} \\
& -\mu_{h} \cdot\left(X_{s}-X_{l}-X_{i l}\right)-E\left[C_{G, h}\right]
\end{aligned}
$$

where $\mu_{h}$ denotes marginal home environmental damage. Three points should be noted. First, because the government revenue from fine is income redistribution from home collectors to the home government, it is not explicitly specified in (31). Second, the numerator of the third term represents the quantity of discarded goods which home collectors fail to export illegally (see (15) and (16)). Third, the home government also faces the landfill scarcity and leakage of toxic substances from landfills. Hence, the amount of waste disposed into home landfills, $X_{s}-X_{l}-X_{i l}$, has a negative impact on the home welfare.

Foreign welfare is defined as the sum of consumer surplus from secondhand goods and recyclable materials, the producer surplus of foreign collectors, and government revenue from fine payments less the foreign environmental damage and policy enforcing cost:

$$
\begin{aligned}
E\left[W_{f}\right]= & \int_{0}^{D_{u}} p_{u}(\varsigma) d \varsigma-p_{u} D_{u}+\int_{0}^{D_{m}} p_{m}(\psi) d \psi-p_{m} D_{m} \\
& +\int_{0}^{X_{F}}\left(p_{m}-M C_{f}(\omega)\right) d \omega+\frac{\alpha_{f}}{1-\alpha_{f}} \cdot F_{f} \cdot X_{i l} \\
& -\left(\mu_{u, f} \cdot X_{u}+\mu_{m, f} \cdot X_{m}+\mu_{i l, f} X_{i l}^{*}-\mu_{w, f} \cdot X_{F}\right)-E\left[C_{G, f}\right] .
\end{aligned}
$$

\subsection{Monitoring Game}

Because the seriousness of environmental damage arising from legally imported secondhand goods, legally imported recyclable materials, and illegally imported recyclable materials are different from each other, for the first-best situation to be achieved, both home and foreign governments should use policies that directly influence environmental damage, such as waste tax and emission charges. Moreover, the markets of secondhand goods and recyclable materials should be separated. However, we do not consider such kinds of policies. Thus, the globally optimal monitoring policy in this subsection is one of the second-best situations.

As the level of trade restriction is exogenous, the first-order conditions (FOCs) for determining globally optimal monitoring probabilities are given by

$$
\frac{\partial\left(E\left[W_{h}\right]+E\left[W_{f}\right]\right)}{\partial \alpha_{h}}=0, \quad \frac{\partial\left(E\left[W_{h}\right]+E\left[W_{f}\right]\right)}{\partial \alpha_{f}}=0 .
$$

We regard the combination of monitoring probabilities that satisfies the aforementioned FOCs 


\section{K. Higashida}

as a cooperative equilibrium. We also assume that the second-order conditions (SOCs) hold.

By contrast, when each government selects its monitoring probability noncooperatively, from (31) and (32), the FOCs are

$$
\begin{gathered}
\frac{\partial E\left[W_{h}\right]}{\partial \alpha_{h}}=\gamma_{h} X_{l}-\frac{\alpha_{f} \gamma_{h} \gamma_{f}\left(D_{u}^{\prime}+D_{m}^{\prime}-X_{F}^{\prime}\right)}{1-\alpha_{f}}-\frac{C_{d}}{\left(1-\alpha_{h}\right)^{2}\left(1-\alpha_{f}\right)} \\
+\mu_{h} \gamma_{h}\left(D_{u}^{\prime}+D_{m}^{\prime}-X_{F}^{\prime}\right)-\frac{d E\left[C_{G, h}\right]}{d \alpha_{h}}=0, \\
\frac{\partial E\left[W_{f}\right]}{\partial \alpha_{f}}=\left(1-\alpha_{h}\right) \gamma_{f} \cdot\left(X_{F}-D_{u}-D_{m}\right)+\frac{F_{f} X_{i l}}{\left(1-\alpha_{f}\right)^{2}} \\
+\frac{\alpha_{f} \gamma_{f} F_{f}\left(1-\alpha_{h}\right)\left(D_{u}^{\prime}+D_{m}^{\prime}-X_{F}^{\prime}\right)}{1-\alpha_{f}} \\
-\gamma_{f}\left(1-\alpha_{h}\right)\left(\mu_{u, f} D_{u}^{\prime}+\mu_{m, f} X_{l}^{\prime}+\mu_{i l} X_{i l}^{\prime}-\mu_{w, f} X_{F}^{\prime}\right)-\frac{d E\left[C_{G, f}\right]}{d \alpha_{f}}=0,
\end{gathered}
$$

where

$$
\gamma_{h}=F_{h}-\alpha_{f}\left(F_{f}+\lambda\right), \quad \gamma_{f}=F_{f}+\lambda .
$$

Note that the partial derivatives of (13) are used to derive the second term of (33) and the third term of (34).

For the home country, an increase in its own monitoring probability increases the surplus from legal exports, decreases fine payments to the foreign government, decreases the total disguising cost, increases loss from failure of illegal exports, increases home environmental damage as a result of a decrease in total exports of discarded goods $X$, and increases the policy enforcing cost. On the other hand, for the foreign country, an increase in its own monitoring probability decreases the sum of consumer and producer surplus because the price of recyclable materials increases and the total consumption is larger than the foreign domestic supply. The effect on fine revenue is ambiguous. An increase in monitoring probability directly increases fine revenue, while it decreases the incentive of home collectors for exporting discarded goods illegally. The latter indirect effect decreases fine revenue. Moreover, as discussed in Subsection 3.2, the effect on foreign environmental damage depends on the relative sizes of the marginal environmental damage caused by secondhand use and recycling of legally and illegally imported recyclable materials.

The second partial derivatives are written as follows.

$$
\begin{gathered}
\frac{\partial^{2} E\left[W_{h}\right]}{\partial \alpha_{h}^{2}}=\left\{F_{h}-\alpha_{f}\left(F_{f}+\lambda\right)\right\}^{2} X_{l}^{\prime}-\frac{2 C_{d}}{\left(1-\alpha_{h}\right)^{3}\left(1-\alpha_{f}\right)}-\frac{d^{2} E\left[C_{G, h}\right]}{d \alpha_{h}^{2}}, \\
\frac{\partial^{2} E\left[W_{f}\right]}{\partial \alpha_{f}^{2}}=\gamma_{f}\left(1-\alpha_{h}\right)\left(D_{u}^{\prime}+D_{m}^{\prime}-X_{F}^{\prime}\right) \cdot\left\{\frac{F_{f}}{\left(1-\alpha_{f}^{2}\right)}-\gamma_{f}\left(1-\alpha_{h}\right)\right\}+\frac{2 F_{f} X_{i l}}{\left(1-\alpha_{f}\right)^{3}}-\frac{d^{2} E\left[C_{G, f}\right]}{d \alpha_{f}^{2}},
\end{gathered}
$$




$$
\begin{aligned}
\frac{\partial^{2} E\left[W_{h}\right]}{\partial \alpha_{f} \partial \alpha_{h}}= & -\gamma_{f} X_{l}+\gamma_{h} \gamma_{f}\left(1-\alpha_{g}\right) X_{l}^{\prime}-\frac{C_{d}}{\left(1-\alpha_{h}\right)^{2}\left(1-\alpha_{f}\right)^{2}} \\
& -\left\{\frac{\gamma_{h}}{\left(1-\alpha_{f}\right)^{2}}+\frac{\alpha_{f} \gamma_{f}}{1-\alpha_{f}}-\mu_{h}\right\} \cdot \gamma_{f}\left(D_{u}^{\prime}+D_{m}^{\prime}-X_{F}^{\prime}\right), \\
\frac{\partial^{2} E\left[W_{f}\right]}{\partial \alpha_{h} \partial \alpha_{f}}= & \gamma_{f}\left(D_{u}+D_{m}-X_{F}\right)-\left(1-\alpha_{h}\right) \gamma_{h} \gamma_{f}\left(D_{u}^{\prime}+D_{m}^{\prime}+X_{F}^{\prime}\right) \\
& +\left\{\frac{F_{f} \gamma_{h}}{\left(1-\alpha_{f}\right)^{2}}-\frac{\alpha_{f} F_{f} \gamma_{f}}{1-\alpha_{f}}\right\} \cdot\left(D_{u}^{\prime}+D_{m}^{\prime}+X_{F}^{\prime}\right) \\
& +\gamma_{f}\left(\mu_{u, f} D_{u}^{\prime}+\mu_{m, f} X_{l}^{\prime}+\mu_{i l} X_{i l}^{\prime}-\mu_{w, f} X_{F}^{\prime}\right) .
\end{aligned}
$$

In the following, we assume that the second-order conditions (SOCs) are satisfied:

$$
\frac{\partial^{2} E\left[W_{h}\right]}{\partial \alpha_{h}^{2}}<0, \quad \frac{\partial^{2} E\left[W_{f}\right]}{\partial \alpha_{f}^{2}}<0 .
$$

Moreover, the stability condition is assumed to be satisfied:

$$
\frac{\partial^{2} E\left[W_{h}\right]}{\partial \alpha_{h}^{2}} \cdot \frac{\partial^{2} E\left[W_{f}\right]}{\partial \alpha_{f}^{2}}-\frac{\partial^{2} E\left[W_{h}\right]}{\partial \alpha_{f} \partial \alpha_{h}} \cdot \frac{\partial^{2} E\left[W_{f}\right]}{\partial \alpha_{h} \partial \alpha_{f}}>0 .
$$

Let $\alpha_{i}^{N}(i=h, f)$ denote the equilibrium probabilities in the noncooperative Nash equilibrium. We also refer to this equilibrium as the simultaneous move equilibrium. In the following, we focus on the case wherein both governments choose positive amounts of monitoring probabilities. As noted, the home government can save the welfare loss caused by the identification of illegal trade by foreign customs and increase the producer surplus of home collectors by increasing its monitoring probability. Thus, it follows from (33) that the home government is likely to choose a positive monitoring probability unless (a) $X_{l}$ is very small, (b) $C_{d}$ is large, (c) $\mu_{h}$ is large, and (d) demand for secondhand goods and recyclable materials in the foreign country and the foreign domestic supply are inelastic. ${ }^{32)}$ The foreign government is likely to choose a positive monitoring probability when the environmental damage is serious and an increase in the monitoring probability decreases the foreign environmental damage.

From (31) and (32), we obtain the following partial derivatives:

$$
\begin{gathered}
\frac{\partial E\left[W_{h}\right]}{\partial \alpha_{f}}=\gamma_{f} X_{l}-\frac{\alpha_{f} \gamma_{f}^{2}\left(D_{u}^{\prime}+D_{m}^{\prime}-X_{F}^{\prime}\right)}{1-\alpha_{f}} \\
-\frac{\gamma_{f} X_{i l}}{1-\alpha_{f}}-\frac{C_{d}}{\left(1-\alpha_{h}\right)\left(1-\alpha_{f}\right)^{2}}+\mu_{h} \gamma_{f}\left(D_{u}^{\prime}+D_{m}^{\prime}-X_{F}^{\prime}\right), \\
\frac{\partial E\left[W_{f}\right]}{\partial \alpha_{h}}=\left(1-\alpha_{h}\right) \gamma_{h} \cdot\left(X_{F}-D_{u}-D_{m}\right)+\frac{\alpha_{f} \gamma_{h} F_{f}\left(1-\alpha_{h}\right)\left(D_{u}^{\prime}+D_{m}^{\prime}-X_{F}^{\prime}\right)}{1-\alpha_{f}} \\
-\gamma_{h}\left(1-\alpha_{h}\right)\left(\mu_{u, f} D_{u}^{\prime}+\mu_{m, f} X_{l}^{\prime}+\mu_{i l} X_{i l}^{\prime}-\mu_{w, f} X_{F}^{\prime}\right) .
\end{gathered}
$$

First, compare (34) and (41). The three terms in (41) are identical to the first, third, and

32) Inelastic demand and supply means that the absolute values of $D_{u}^{\prime}, D_{m}^{\prime}$, and $X_{F}^{\prime}$ are small. 


\section{K. Higashida}

fourth terms in (34) if $\gamma_{f}$ in (34) is substituted for by $\gamma_{h}$. Then, the sign of (41) depends on absolute values of the second and fifth terms in (34) when considering the sign at $\partial E\left[W_{f}\right] / \partial \alpha_{f}=0$. If the foreign environmental damage is not serious and, accordingly, if $\alpha_{f}$ is very low, it is likely that $d E\left[C_{G, f}\right] / d \alpha_{f}$ is relatively small. Thus, the effect on the fine revenue (the second term) is greater than the effect on the policy enforcing cost (the fifth term). In such a case, (41) is negative. The reason is as follows. As the foreign monitoring probability is low, quantities of illegal and total imports are large. Thus, the loss of consumer surpluses from a decrease in imports due to an increase in the home monitoring probability dominates the benefits from a decrease in environmental damage. On the other hand, in cases where the foreign environmental damage is serious, focusing on the simultaneous move equilibrium, it is likely that $\alpha_{f}$ is relatively large, because the foreign government deal with the environmental damage by setting a high monitoring probability even if the marginal cost of increasing the monitoring probability dominates the marginal increase in fine revenue. In such cases, the effect on the fine revenue (the second term) is smaller than the effect on the policy enforcing cost (the fifth term). In such cases, (41) is positive.

Second, compare (33) and (40). The first, second, and fourth terms in (33) are the same as the first, second, and fifth terms in (40), respectively, if $\gamma_{h}$ in (33) is substituted for by $\gamma_{f}$. Then, the sign of (40) depends on the absolute values of the third and fifth terms in (33) and the absolute values of the third and fourth terms in (40) when considering the sign at $\partial E\left[W_{h}\right] /$ $\partial \alpha_{h}=0$. If $\alpha_{h}$ is low, it is likely that $d E\left[C_{G, h}\right] / d \alpha_{h}$ is very small. Thus, the negative effect on the fine revenue is greater than the effect on the policy enforcing cost. Moreover, the absolute value of the third term in (33) is smaller than that of the fourth term in (40) when $\alpha_{h}<\alpha_{f}$. In such a case, (40) is likely to be negative. The reason is that the welfare loss caused by an increase in the fine payment to the foreign government and an increase in the loss from failure of illegal exports is serious. Thus, we establish the following result.

Proposition 3 In the simultaneous move equilibrium, the home (foreign) monitoring probability is likely to be lower (higher) than that in the globally optimum, that is, $\partial E\left[W_{f}\right] / \partial \alpha_{h}>0$ and $\partial E\left[W_{h}\right] / \partial \alpha_{f}<0$, if the home environmental damage is not very serious while the foreign environmental damage is serious.

\subsection{Commitment}

Given the level of trade restriction, can the commitment for monitoring probabilities by either government improve the welfare of both countries? There are various possible cases for answering this question. Thus, we focus on one of such interesting cases to demonstrate the existence of situations in which commitment can be Pareto improving.

First, consider the sign of (38). An increase in foreign monitoring probability weakens the marginal effect of an increase in the home monitoring probability on the price change of recyclable material. In this respect, the home government's incentive for increasing its monitoring probability becomes weaker (the first term). On the other hand, an increase in the foreign monitoring probability increases the legal exports. In this respect, the home government's incentive for increasing its monitoring probability becomes stronger because the positive effect on an increase in the producer surplus of home collectors becomes larger (the second term). An increase in the foreign monitoring probability increases the attempt of illegal exports 
Trade in Secondhand Goods and Recyclable Materials, Monitoring of Illegal Trade, and Import Quotas on Legal Trade

because as far as the gap between the price of recyclable material and the expected illegally exporting cost exists, home collectors have incentives to export discarded goods illegally. Subsequently, because the effect of a small increase in the home monitoring probability on the loss from failure of illegal exports becomes larger, the home government's incentive for increasing its monitoring probability becomes weaker (the third term). Moreover, the home government has a stronger incentive for increasing its monitoring probability in terms of the fine revenue, while it has a weaker incentive in terms of the home environmental damage (the fourth term). In total, the sign of (38) may be positive or negative. However, when (a) the demand for secondhand goods and recyclable materials in the foreign country is elastic, and (b) the home environmental damage is moderate, it is likely that (38) is positive.

Second, consider the sign of (39). An increase in the home monitoring probability weakens the marginal effect of an increase in the foreign monitoring probability on the price change of recyclable material. In this respect, the foreign government's incentive for increasing its monitoring probability becomes stronger because the loss from an increase in the price of recyclable materials becomes smaller (the first term). Furthermore, an increase in the home monitoring probability decreases the consumption of secondhand goods and recyclable materials in the foreign country. Thus, the loss of consumer surplus caused by an increase in the foreign monitoring probability becomes smaller, which provides the foreign government with a stronger incentive for increasing its monitoring probability (the second term). The third and fourth terms are the effect arising from tax revenue and environmental damage, respectively. In total, the sign of (39) may be positive or negative. However, focusing on the case in which the foreign environmental damage is serious and an increase in the foreign monitoring probability decreases the foreign environmental damage, the fourth term is negative and dominates other conflicting effects. Thus, (39) is negative.

Combining the results regarding signs of partial and cross derivatives in the previous and present subsections, we consider the case in which (38) and (41) are positive while (39) and (40) are negative. This situation is shown in Figure 5. The horizontal (vertical) axis measures the home (foreign) monitoring probability, and $R_{h}\left(R_{f}\right)$ is the reaction function of the home

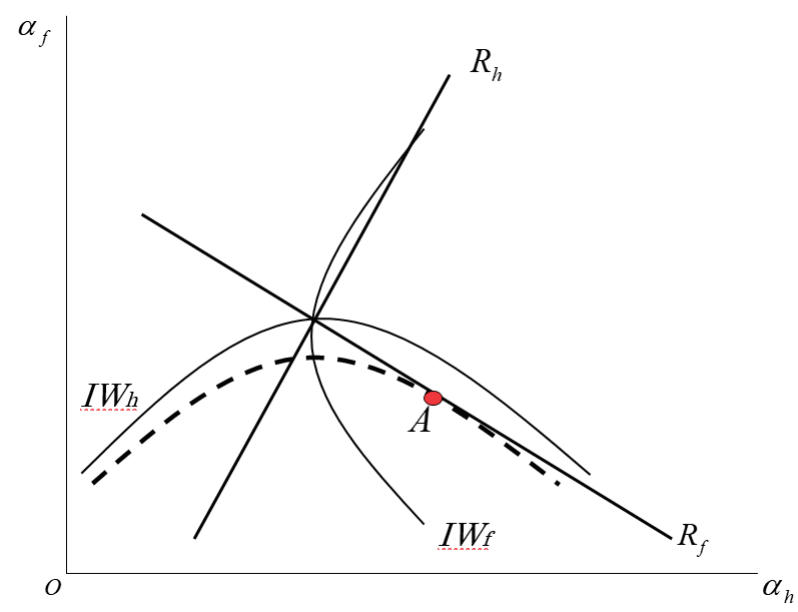

Figure 5: An equilibrium in the monitoring game and commitment. 


\section{K. Higashida}

(foreign) government. Moreover, $I W_{h}$ and $I W_{f}$ are the home and foreign iso-welfare curve, respectively. In this case, it is clear that the commitment by the home government improves the welfare of both countries (see point $A$ in Figure 5). In other words, the change in the game structure from the simultaneous moving to the sequential moving, in which the home (foreign) government moves first (second), is Pareto improving.

As noted, there are various cases depending on signs of the four equations, (38), (41), (39), and (40). However, the result obtained in this subsection indicates that there is a situation in which the commitment by either government can improve the welfare of both countries.

\section{Conclusion}

By assuming that the home (foreign) country exports (imports) secondhand goods and recyclable materials, we examined monitoring policies on illegal trade and import restrictions on legal trade. We primarily focused on the level of environmental damage in importing countries. Further, we investigated the behavior of both governments in choosing their own monitoring probabilities.

First, we demonstrated that a stricter monitoring - an increase in the monitoring probability - by an importing country necessarily decreases the environmental damage of the importing country when there are no legal imports of recyclable materials, while they may increase environmental damage when a part of legal imports are recyclable materials.

Second, we demonstrated that a stricter trade restriction by an importing country on legal imports increases the environmental damage of the importing country if a part of legal imports is recyclable materials and the marginal environmental damage caused by illegal trade is more serious than that caused by legal trade of recyclable materials.

Third, we show that in the simultaneous move equilibrium wherein both governments choose the strictness of monitoring simultaneously, the monitoring probability of the exporting (importing) country is likely to be lower (higher) than that in the globally optimum, if the environmental damage of the exporting (importing) country is not serious (serious). The result also depends on the policy effect on fine revenue and the loss from failure of illegal exports.

Fourth, we consider the commitment to the monitoring probability by governments. We show a case in which the commitment by the home government can improve the welfare of both countries.

We have not considered two interesting factors in this paper. First, we excluded the change in the international (exporting) price of illegal exports by assuming a constant marginal cost of illegal exports. However, Chen et al. (2019) demonstrated that strict monitoring policies decrease not only illegal trade but also the import price of materials. It is interesting to generalize the present model and consider the upward sloping of the marginal cost curve of illegal exports. Second, we have not considered the optimal level of import restriction. As highlighted by several studies (Wang et al., 2019; Huan et al., 2020; Wang et al., 2020; Junbo et al., 2019; Liu et al., 2020), the complete ban of imports of recyclable materials leads to shortage of materials as input in the importing countries and the waste problem in the exporting countries, at least in the short run. Thus, it is important to elaborate proper trade networks and recycling policies with moderate trade restrictions. These extensions are interesting future tasks. 
Trade in Secondhand Goods and Recyclable Materials, Monitoring of Illegal Trade, and Import Quotas on Legal Trade

\section{Reference}

Alberini, A. and Austin, D.H. (1999). Strict liability as a deterrent in toxic waste management: Empirical evidence from accident and spill data. Journal of Environmental Economics and Management, 38 : 20-48.

Almer, C. and Goeschl, T. (2010). Environmental crime and punishment: Empirical evidence from the German penal code. Land Economics, 86: 707-726.

Baggs, J. (2009). International trade in hazardous waste. Review of International Economics, 17: 1-16.

Berglund, C. and Söderholm, P. (2003a). Complementing empirical evidence on global recycling and trade of waste paper. World Development, 31: 743-754.

Berglund, C. and Söderholm, P. (2003b). An econometric analysis of global waste paper recovery and utilization. Environmental and Resource Economics, 26: 429-456.

Cassing, J. and Kuhn, T. (2003). Strategic environmental policies when waste products are tradable. Review of International Economics, 11: 495-511.

Chatterjee, N., Gupta, K. and Chatterjee, T. (2015). Revisiting the conflicts between environmental taxes vs standard in the context of international trade: The role of waste recycling. MPRA Paper \#64709.

Chen, L., Garcia-Medina, B.C. and Wan, R. (2019). Trade liberalization, consumption shifting and pollution: Evidence from Mexico's used vehicle imports. Review of International Economics, 27: 15911608 .

Clerides, S. and Hadjiyiannis, C. (2008). Quality standards for used durables: an indirect subsidy? Journal of International Economics, 75: 268-282.

Copeland, B.R. (1991). International trade in waste products in the presence of illegal disposal. Journal of Environmental Economics and Management, 20: 143-162.

D'Amato, A., Mazzanti, M. and Nicolli, F. (2015). Waste and organized crime in regional environments: How waste tariffs and the mafia affect waste management and disposal. Resource and Energy Economics, 41: 185-201.

Hamilton, J.H. and Slutsky, S.M. (1990). Endogenous timing in duopoly games: Stackelberg or Cournot equilibria. Games and Economic Behavior, 2: 29-46.

Harford, J.D. (1978). Firm behavior under imperfectly enforceable pollution standards and taxes. Journal of Environmental Economics and Management, 5: 26-43.

Harford, J.D. (1987). Self-reporting of pollution and the firm's behavior under imperfectly enforceable regulation. Journal of Environmental Economics and Management, 14: 293-303.

Honma, S. (2019). Optimal policies for international recycling between developed and developing countries. Letters in Spatial and Resource Sciences, 12: 143-153.

Huang, Q., Chen, G., Wang, Y., Chen, S., Xu, L. and Wang, R. (2020). Modelling the global impact of Chinas ban on plastic waste imports. Resources, Conservation \& Recycling, 154: 104607.

Ilankoon, I.M.S.K., Ghorbani, Y., Chong, M.N., Herath, G., Moyo, T. and Peterson, J. (2018). E-waste in the international context A review of trade flows regulations, hazards, waste management strategies and technologies for value recovery. Waste Management, 82: 258-275.

Ino, H. (2011). Optimal environmental policy for waste disposal and recycling when firms are not compliant. Journal of Environmental Economics and Management, 62(2): 290-308.

Junbo, W., Yiyi, J., Minxi, W. and Xin, L. (2019). Scenario analysis of the recycled copper supply in China considering the recycling efficiency rate and waste import regulations. Resources, Conservation \& Recycling, 146: 580-589.

Kellenberg, D. (2010). Consumer waste, backhauling, and pollution havens. Journal of Applied Economics, 13: 283-304.

Kellenberg, D. (2012). Trading wastes. Journal of Environmental Economics and Management, 64: 6887.

Kellenberg, D. (2015). The economics of international trade of waste. Annual Review of Resource Economics, 7: 109-125. 


\section{K. Higashida}

Kellenberg, D. and Levinson, A. (2014). Waste of effort? International environmental agreements. Journal of Association of Environmental and Resource Economists, 1: 135-169.

Kellenberg, D. and Levinson, A. (2019). Misreporting trade: Tariff evasion, corruption, and auditing standards. Review of International Economics, 27: 106-129.

Kinnaman, T. and Yokoo, H. (2011). The environmental consequences of global reuse. American Economic Review, 101: 71-76.

Liu, S., Zhang, Y., Su, Z., Lu, M., Gu, F., Liu, J. and Jiang, T. (2020). Recycling the domestic copper scrap to address the China's copper sustainability. Journal of Materials Research and Technology, Forthcoming.

Macho-Stadler, I. and Pérez-Costrillo, D. (2006). Optimal enforcement policy and firms' emissions and compliance with environmental taxes. Journal of Environmental Economics and Management, 51: $110-131$.

Parajuly, K., Thapa, K.B., Cimpan, C. and Wenzel, H. (2018). Electronic waste and informal recycling in Kathmandu, Nepal: Challenges and opportunities. Journal of Material Cycles and Waste Management, 20: 656-666.

$\mathrm{Pu}$, Y., Wu, G., Tang, B., Xu, L. and Wnag, B. (2019). Structural features of global recycling trade networks and dynamic evolution patterns. Resources, Conservation \& Recycling, 151: 104445.

Ray, A. (2008). Waste management in developing Asia: can trade and cooperation help? Journal of Environment and Development, 17: 3-25.

Shimshack, J.P. (2014). The economics of environmental monitoring and enforcement. Annual Review of Resource Economics, 6: 339-360.

Shinkuma, T. and Huong, N.T.M. (2009). The flow of E-waste material in the Asian region and a reconsideration of international trade policies on E- waste. Environmental Impact Assessment Review, 29: 2531.

Shinkuma, T. and S. Managi (2011). Waste and Recycling - Theory and empirics - . Routledge.

Stafford, S. (2003). Assessing the effectiveness of state regulation and enforcement of hazardous waste. Journal of Regulatory Economics, 23: 27-41.

Sun, M. (2019). The effect of border controls on waste imports: Evidence from China's Green Fence campaign. China Economic Review, 54: 457-472.

Van Beukering, P.J.H. and Bouman, M.N. (2001). Empirical evidence on recycling and trade of paper and lead in developed and developing countries. World Development, 29: 1717-1737.

Wang, C., Zhao, L., Lim, M.K., Chen, W. and Sutherland, J.W. (2020). Resources, Conservation \& Recycling, 153, 104591.

Wang, W., Themelis, N.J., Sun, K., Bourtsalas, A.C., Huang, Q. and Zhang, Y. (2019). Current influence of China's ban on plastic waste imports. Waste Disposal \& Sustainable Energy, 1: 67-78.

Wong, M.H., Wu, S.C., Deng, W.J., Yu, X.Z., Luo, Q., Leung, A.O.W., Wong, C.S.C., Luksemburg, W.J. and Wong, A.S. (2007). Export of toxic chemicals? A review of the case of uncontrolled electronicwaste recycling. Environmental Pollution, 149: 131-140.

Yokoo, H. and Kinnaman, T.C. (2013). Global reuse and optimal waste policy. Environment and Development Economics, 18: 595-614. 